\title{
La vacuidad cultural como sistema histórico prometedor de una sustancialidad poética en José Lezama Lima
}

MARIE-Christine SEgUIN Post-doctorante de la Universidad Toulouse II le Mirail (Francia) Ponencia del 18-21 de julio de 2000 para el V Congreso Centroamericano de Historia, San Salvador.

El fenómeno de la vacuidad cultural consta de varios aspectos político-sociales de la realidad cubana de la primera mitad del siglo veinte. Los trastornos político-sociales afectaron la producción literaria y limitaron los recursos del intelectual que expresaba la realidad conforme con las carencias identitarias. Sin embargo, desde la perspectiva lezamiana, la vacuidad cultural y las influencias variadas, tales como los aportes de culturas ajenas, no son antagónicas, puesto que el ser cubano no tiene que borrar las influencias griegas, renacentistas italianas y las tendencias barrocas españolas, sólo por no haberse creado en la tierra cubana, sino que el aporte de esas tendencias occidentales forman parte de su historia con más que hubo un sincretismo obvio a partir de las fuentes originales. Según la procedencia y la permeabilidad de tales fuentes se plasmó el género cubano como en cualquier otra sociedad. La vacuidad cultural sólo se justifica cuando los modelos no se encajan con los fragmentos identitarios del país, o que no hay elección posible entre la diversidad de las fuentes ni deseo de conformarse con esos modelos.

"La vacuidad cultural como sistema histórico prometedor de una sustancialidad poética 
A partir de aquí se entiende la frustración de los intelectuales que no pudieron más que aspiran por la negativa a la trascendencia del largo período de la "República mediatizada", esto es, la etapa entre la liberación española y la revolución fidelista, que fue vivida como un verdadero fraude de lo que era propio de la realidad cultural cubana. Para definir el problema mayor del hombre americano, Julio Rodríguez Luis no vacila en presentar las dos vertientes de una identidad, entendida entre un compromiso y un experimento hacia la superación de una vacuidad histórica más global. Este estado procede de un proceso cultural incompleto o subdesarrollado según las relaciones establecidas entre el hombre y su historia, dice a propósito: "la memoria identifica el estado de desarrollo con el de civilización, —entendida desde un punto de vista espiritual en vez de meramente material- $y$, por lo tanto con la capacidad, (...), de entenderse a sí mismo, que es el único vehículo, a través del distanciamiento respecto a los problemas personales, que resulta de esa capacidad, de comprender la realidad histórica en la que nos hallamos inmersos, y la propia relación con ella". El desfase que se creó entre el hombre y la realidad histórica impuesta, en el enfoque del principio del siglo hasta los años 50 en Cuba, sólo pudo desembocar en una reacción defensiva que no podía ser superada sin ser dilucidada. El marco histórico tenía que aparecer de alguna forma en el fundamento de lo que iba a ser el porvenir cultural cubano.

\section{La vacuidad cultural vinculada con el marco temporal de la "Re- pública mediatizada"}

Los primeros esfuerzos en este sentido fueron, por parte del joven José Lezama Lima, unas reacciones al escrito poco enriquecedor, aunque innovador en su intento, practicado por los poetas del Grupo Minorista o los de la Revista de Avance, cuyo fondo común era luchar contra la incapacidad de los jefes sucesivos de la "República mediatizada". A principios de este período que va de 1895 a 1913, la literatura se nos presenta mediocre, dice Cintio Vitier: "se puede destacar la continuación de la poesía patriótica, de la poesía nativista o tipicista, la del paisaje cubano, y la influencia de Julián del Casal"' La influencia de José Martí todavía no se podía sentir, por lo temprano de su fallecimiento. Pero ya desde 1927 el joven Lezama Lima investigaba una escapatoria entre las variadas producciones hechas polémicas de la sociedad. Tenía que contornear aquella contienda y colocar el 
litigio en un área propia de lo cultural y de lo literario. Aunque los intentos convergieron hacia ese deseo experimentado por los poetas, nadie consiguió lo que Lezama Lima estaba elaborando en su sistema poético. Entre ambos siglos, poetas como Bonifacio Byrne (1861) formaron un clan afiliado a una poesía patriótica que cantaba los días de la liberación, pero muy pronto expresó su angustia ante la prolongada intervención norteamericana y la presencia de las dos banderas en el Castillo del Morro, en su poema "Mi bandera": "Al volver de distante ribera,/ con el alma enlutada, y sombría,/ afanoso busqué mi bandera/ iy otra he visto además de la mía" ${ }^{3}$. De la misma manera, los poetas de la segunda generación de la era republicana, fueron entre los primeros en dar cuenta de este fraude, impeliendo la creación verbal hacia la superación de la realidad e intentando salvarla a la vez. Regino Botti en su poema "El café" recuerda los apuntes del último diario de Martí, pero "desprovisto de esperanza" dice Cintio Vitier, y José Manuel Poveda se propone un rescate de la Nación a través de sus "Versos precursores", pero "lo que les faltó, [aduce Cintio Vitier], fue una visión de la realidad y una incorporación de la cultura que hiciera posible esa especie de fundación desde la palabra; un centro unitivo y una amplitud de radios que logrará el círculo mágico de la fortaleza en el desierto"4.

Lo que va a conseguir Lezama Lima, en medio de los trastornos socio-políticos del país, es esta imantación de fragmentos identitarios que permiten divisar, en un primer tiempo, la superación de la coyuntura. En las revistas Verbum y Espuela de Plata del 39 y del 41 aparecen sus reivindicaciones literarias y poéticas. En ellas plantea el problema de hallar el lugar de la pura identidad cultural a través de todos las contradicciones sociales. El impulso innovador no consiste sólo en rechazar la realidad o en poetizarla ${ }^{5}$, sino en ir más allá de esta finalidad por una vía que Lezama Lima llama "hipertelia", —es decir más allá de las finalidades-, para acertar un espacio puramente lírico, formado a base de conceptos e ideas conformes con la que el poeta experimenta como la identidad cultural cubana. No sólo quiere desplazar esa contienda sino que desea elaborar un sistema que corresponda al ser-poeta cubano. Y este sistema se despliega por la creación de unas eras imaginarias reagrupando nociones históricas hasta conceptos filosóficos que concretan una percepción del mundo cubano, a pesar de su universalidad. El esfuerzo mayor de Lezama Lima en aquel período

"La vacuidad cultural como sistema histórico prometedor de una sustancialidad poética 
inestable de la "República mediatizada" es concretar un sistema que pueda oficiar como una re-creación de un patrimonio literario. La situación apremiante ha podido servir a la creación temprana del poeta, puesto que aquellos años fueron decisivos en la construcción poética de Lezama Lima. Intenta destacar la especificidad insular hallando las herencias culturales. No padece un exceso criollista, ni tampoco rechaza globalmente la herencia peninsular. Sólo conserva lo que le parece vincular los enlaces culturales entre la cubanidad y la hispanidad. Su camino no es más que el de encontrar la esencia de la cultura, superando las fronteras espaciales y temporales. Seguro que carece de objetividad y que no se conforma con la ideología revolucionaria de la etapa fidelista, pero su cosmopolitanismo responde a un deseo de remediar a una vacuidad obsesiva, creada a raíz de los sucesivos fraudes que experimentó al inicio de su carrera.

\section{Primer instrumento de la razón histórica hacia lo imaginario en Lezama Lima}

En una perspectiva histórica, la era que brinda las herramientas contra la vacuidad cultural es la era décima. Esta era refleja el punto de partida de la posibilidad infinita de la imagen poética a partir de la pobreza del siglo XIX y a partir de las acciones de los liberadores de Cuba. Íntimamente vinculada con la figura de José Martí, como reacción a la falsa riqueza y a la pobreza irradiante, la etapa de la liberación es una revelación de la posibilidad infinita de la imagen poética en cuanto a la generación del individuo desde la pobreza del espíritu. Dice Lezama Lima: "La última era imaginaria (...) es la posibilidad infinita, que entre nosotros la acompaña José Martí. Entre las mejores cosas de la revolución cubana, reaccionando contra la era de la locura que fue la etapa de la disipación, de la falsa riqueza, está el haber traído de nuevo el espíritu de la pobreza irradiante, del pobre sobreabundante por los dones del espíritu. En siglo XIX, el nuestro fue creador desde la pobreza." En relación con esta aseveración, el poeta cambia radicalmente de óptica entre los años 30 y 40 y en uno de los ejemplos nos lega su nuevo campo de batalla. En efecto, nos presenta un cambio entre dos versiones de un mismo poema llamado "Bahía de la Habana" en el 36 y "Fiesta callada" en el $41^{7}$. Gracias a este trabajo, el poeta nos permite apreciar la orientación de su lucha por lo literario y por el rescate de un pensamiento intelectual que 
tiene como meta principal la de rechazar las coordenadas socio-políticas de aquel entonces. Particularmente enlazados a la era republicana, esas dos versiones dan cuenta de una esperanza en la fe de un sistema literario que pueda imantar los fragmentos identitarios. La infinita posibilidad de la historia de la nación se alza al lado del vacío y de la muerte, dijo también en sus ensayos. Hacer de una debilidad una fuerza es uno de los principios creadores de la poesía de Lezama Lima. La pugna poética se sitúa ahora en esta vertiente imaginaria, en que las paradojas puedan asombrar, en que los conceptos puedan ser irracionales pero siempre rescatados por un esfuerzo de imantación cuya atracción es la ruptura de la vacuidad. Este principio clave tanto de la construcción poética como del estilo que se desencadena, por lo prolijo de las frases, corresponden al anhelo de rellenar cada intersticio hueco de imágenes. Entre las dos versiones de los poemas "Bahía de la Habana" y "Fiesta callada", la evolución entre lo real y lo imaginario es obvia, y más aún la trascendencia de lo real por la alegoría que se construye a raíces de metáforas numerosas, las cuales definen no una realidad poetizada pero sí un mundo cultural imaginario primero. Frente al vacío y al silencio en que se extravió la identidad cubana, el poeta se empeña en alcanzar otra orilla que consigue vincular con lo meramente lírico.

\section{Superación de lo histórico hacia los fragmentos identitarios de una sustencialidad poética}

José Lezama Lima decide crear un centro magnético del conocimiento a prueba del tiempo y del espacio, que nombra "Cantidad hechizada", en el que figuran las eras imaginarias como medidas temporales, las cuales representan una elección de lo que puede sustentar al ser cubano. El poeta mide la distancia entre la era décima ligada a la historia cubana y otras eras culturales en que aparecen una preocupación por el principio de la vacuidad. La era de las fundaciones chinojaponesa, o la Biblioteca como dragón, es el segundo espacio-tiempo en que coincide el problema de la vacuidad como sistema de fundación de la realidad imaginaria poética. La era de la Biblioteca como dragón expresa la mayor preocupación filosófica acerca de los sistemas del lleno y del vacío. En ella se destaca el deseo de hallar los conceptos que justifican la trinidad taoísta de "lo invisible (mirado sin ser visto); de lo inaudible (escuchado sin ser oído); y lo intangible

'La vacuidad cultural como sistema histórico prometedor de uno sustancialidad poética 
(tomado sin ser tocado)"8. La obsesión del vacío se convierte en un principio-clave para conseguir la inmortalidad a través de la imagen poética. La vacuidad se materializa en un espacio según la tradición china o en armonía con los canones clásicos del Libro del té. Las ceremonias del té en la tradición chino-japonesa realizan la creación de un espacio de meditación, este espacio se convierte en una casa predilecta para la elaboración de la imagen poética: "El Pabellón de la Imagen coincidía con el Pabellón de la Vacuidad y ambos con el Pabellón de lo Informe. La infusión de té era sólo una espera, para que su informidad se fuera trocando, después de componer con toda la diversidad conveniente, en un punto de reto silencioso y en una inmensa condensación que se restituye para formar el Gran Uno."”

En su poema "El Pabellón del vacío" de Fragmentos a su Imán, del 77 dice el poeta:

Necesito un pequeño vacío, alli me voy reduciendo para reaparecer de nuevo, palparme y poner la frente en su lugar.

Me voy reduciendo, soy un punto que desaparece y vuelve y quepo entero en el tokonoma. Me hago invisible $y$ en el reverso recobro mi cuerpo nadando en una playa.

Me duermo, en el tokonoma evapora el otro que sigue caminando.

"Toda siembra profunda, como decían los taoistas, es en el espacio vacío", afirma también en Paradiso (cap IX).

Su preocupación es la de compartir esa nueva percepción del mundo y dejar la denuncia del vacío cultural que lejos de desaparecer se convierte en un vacío enemigo pero relativo al caos universal. Se hace el símbolo del "horror vacui" que experimenta la naturaleza y que desencadena una proliferación de palabras en el Arte poético. Lezama Lima confiesa que los verdaderos dioses de la construcción poética 
son "el caos o hijos de la creación, el vacío o hijos de la acción y la nada, o hijos de la muerte, y el haz de la luz, el hijo de la resurrección" ${ }^{10}$. Estos ingredientes componen y crean la pre-imagen. El concepto de vacuidad queda inherente a la calidad activa de la misión del poeta a partir de una situación original histórica, pero se convierte en una sustancialidad poética que gobierna la posibilidad infinita de la imagen. Remedia al "horror vacui" por la densidad y el espesor que construye a partir de las bases del vacío y del silencio. En "Aclaración total" incluido en la fijeza, de 1949 dice:

Es trabajar en hueco, las gracias operantes, alfileres en el revés del ojo, tú en voluptas voluptatis, llenando, un cántaro al revés, vaciando, vaciando, hasta adquirir el molde de una vaciedad, ridículo gato de yeso en un bostezo, azul, vaciando, vaciando, hasta ver mi mano en la otra mano, mano sobre mano descansado, la mano vaciada en tictac. El vaciado anticipa le retour des cendres o la supuesta sombra de las fingidas cenizas. Trabajar en hueco tiene que partir de la gracia operante y el retorno de las cenizas tiene que estar tirado por los caballos de la gracia operante.

Vaciando, vaciando la sombra que trae el árbol.

Vacío de chorro yerto que ya no es nuestro.

Vaciando los cordones espermáticos de fuente yerta.

Hay que raspar, vaciando, vaciando.

Estos dos elementos que hay que romper son en definitiva imprescindibles a la elaboración de las imágenes poéticas. Son las bases de reconocimiento de una sociedad que se construye gracias a su destrucción. Así son los signos de una época que designa los fragmentos identitarios. Vacuidad y silencio imperentes revelan el camino de una construcción, no por rechazo, sino pasando por la aceptación de su existencia, para poder empezar una nueva edificación. Hay que hallar un sistema que autorice su existencia para poder alcanzar otra etapa

"La vacuidad cultural como sistema histórico prometedor de uno sustancialidad poético 
constructiva. A partir de la historia cubana Lezama Lima encuentra la razón de ser de estos dos conceptos en las culturas chinas, al entender que puedan coincidir las paradojas y que funcionen en una simbiosis natural, y también encuentra, en la meditación cristiana, un espacio propicio a la vacuidad y al silencio. Para hallar el lugar idóneo a la poesía hay que acercarse a la casa de las imagenes o casa del "alibi": "otro lugar" en latín, que le permite a la imaginación hacerse un acontecimiento. "En su primera versión, la del apunte que precede al poema, nos dice que el alibi, es el estado de los místicos católicos,(...), el alibi es para Lezama el estado místico donde la imaginación puede engendrar el sucedido, y cada hecho se transforma en el espejo de las enigmas. (...) La casa del alibi, por tanto, es la absoluta contrapartida gnóstica de esa vacuidad, pero también nace, in extremis, de ella"11. Dice Lezama Lima en el poema "La casa del alibi":

Pues José Martí fue para todos nosotros

la última casa del alibi,

que está en la séptima luna de las mareas, y la penetran los ejércitos y se deshace penetrándonos ${ }^{12}$

Consigue vincular, como nos dice, la era de los libertadores, las acciones de los jefes de la independencia que crean la posibilidad infinita de la imagen poética, con el estado de meditación suprema de los místicos católicos que permite abarcar la magnitud de un espacio de conocimiento de la ruptura de la vacuidad. Es decir que pasó por una fase de enlace entre la vacuidad como concepto histórico y una fase de meditación predilecta a la creación. Este proceso recuerda el método de la Mística cristiana como era la práctica de lo indicible que remitía a las corrientes que subrayaban la alteridad de la divinidad, de la que sólo se puede hablar por vías de contornos o de silencio. En los escritos de Sor Juana Inés de La Cruz y en la estética barroca se hallan estos principios característicos. Pero si el lenguaje del poeta es común a múltiples vías de contornos, también es sonoro y denso. El espesor remedia al silencio y a la vacuidad en su poesía, pero siempre son datos de partida. El poeta brinda un renacer de los sentidos por haber captado este espacio nuclear, esta esfera de vacuidad que es el primer alimento. Este proceso simboliza el regreso hacia un centro magnético que imanta los fragmentos más diversos de la identidad cubana, también exalta un espacio cubano mágico y poético que es, para el poeta, el centro de La Habana, o ciudad de los fundamentos, equiparable a 
un Omphalos o a la ciudad de Delfos. Esta densidad de la casa del "alibi" no es más que una reivindicación hecha forma a partir de lo informe, tal como una escultura que labra el poeta para afinar los contornos. El deseo del poeta es conseguir la materialización de esta vacuidad. Tiene que delimitarla para romperla y mejor aún rellenar los intersticios con cada fragmento que construye la historia del ser-poeta cubano.

\section{Notas}

1. Rodriguez Luis, Julio, La literatura hispanoamericana entre compromiso y experimento, ed. Fundamentos, $\mathrm{N}^{\circ} 90$, Madrid, 1984, p. 86. Intenta, en esta parte, interpretar los sentimientos de los protagonistas de las novelas de Desnoes Memorias del subdesarrollo y de Cabrera Infante, Tres tristes tigres (ambas del $65)$.

2. Vitier, Cintio, Lo cubano en la poesía, ed. Instituto del libro, La Habana, 1970, P 317

3. Lezama Lima, José, Antologia de la poesía cubana, ed. Consejo Nacional de Cultura, Cuba, 1965, Tomo III, p. 574.

4. Vitier, Cintio, op. cit., p. 343.

5. Rodriguez Luis, Julio, "Lezama se limita a adornar la reproducción de la realidad, a poetizarla- que no es lo mismo que trascenderla" op. cit., p. 104

6. Lezama Lima, José, Obras Completas, La Cantidad hechizada, op. cit., p. 838.

7. Veáse la ponencia presentada en el XXV Simposio de Historia y de Antropología de Sonora, del 21 a 26 de febrero de 2000 en México: "Emergencia de una identidad cultural en la época de la "República mediatizada: 'Bahía de la Habana' convertida en una 'Fiesta callada' para un clamor innegable en la poesía de José Lezama Lima", Seguin, Marie-Christine.

8. Lezama Lima, José, Obras Completas, La cantidad hechizada, Aguilar, México, 1975, P. 909

9. Ídem, p. 909

10. Lezama Lima, José, Manuscrito de la Biblioteca Nacional José Martí, La Habana, Ms $\mathrm{N}^{\circ} 1958$, p. 45

11. Vitier, Cintio, Hallazgo de una profecia, Casa de las Américas, La Habana, septoct 1986, p. 33

12. Idem, p. 34 